\title{
(2) OPEN ACCESS \\ Early discharge and rehabilitation in paediatric acquired brain and neurological injury: a transferable model
}

\author{
Rachel Keetley, ${ }^{1}$ Laura Kelly, ${ }^{1}$ William P Whitehouse, ${ }^{1,2}$ Sophie Thomas, ${ }^{1,2}$ \\ Emily Bennett, ${ }^{1}$ Gabriel Chow, ${ }^{1}$ Alison Fletcher, ${ }^{1,3}$ Jane Williams (D) ${ }^{1}$
}

\begin{abstract}
'Department of Paediatric Neurosciences, Nottingham Children's Hospital, Queen's Medical Centre, Nottingham, UK ${ }^{2} S$ chool of Medicine, Queen's Medical Centre, University of Nottingham, Nottingham, UK ${ }^{3} \mathrm{De}$, The Children's Trust, Tadworth Court, Tadworth, UK
\end{abstract}

\section{Correspondence to} Dr Jane Williams, Department of Paediatric Neurosciences, Nottingham Children's Hospital, Queen's Medical Centre, Nottingham NG7 2UH, UK; jane. williams2@nuh.nhs.uk

Received 7 March 2018 Revised 29 August 2018 Accepted 9 September 2018 Published Online First 20 October 2018

\section{Check for updates}

(C) Author(s) (or their employer(s)) 2020. Re-use permitted under CC BY-NC. No commercial re-use. See rights and permissions. Published by BMJ.

To cite: Keetley R, Kelly L, Whitehouse WP, et al. Arch Dis Child Educ Pract Ed 2020;105:41-45.

\begin{abstract}
Children and young people who require rehabilitation following sustaining an acquired brain injury often experience long lengths of stay (LOS) and potentially poorer recovery outcomes due to limited access to therapy and little proactive discharge planning. After stakeholder enquiry we launched a new team and pathway with a primary aim to reduce LOS. The secondary aims were to pilot an outreach model, reduce cost and improve patient and family satisfaction. We achieved a significantly improved change in quality care with a financial gain and increased patient and family satisfaction.
\end{abstract}

\section{SUMMARY}

Paediatric neurorehabilitation (PNR) services after an acquired brain injury (ABI) in the UK are inconsistent ${ }^{1}$ and often absent, despite a national service specification. ${ }^{2}$ Evidence from adult studies of patients with stroke report early rehabilitation improves outcome. ${ }^{3}$

\section{THE PROBLEM}

There was no dedicated PNR team in a tertiary neuroscience unit despite being a major trauma centre. Children and young people (CYP) received inconsistent therapy, had extended stays for want of focused therapy and discharge planning. There was patient and professional dissatisfaction.

\section{AIMS}

This was a quality improvement (QI) initiative, adhering to SMART (Specific, Measurable, Attainable, Relevant \& Timely) objectives, to establish early rehabilitation, proactive discharge planning, shorten length of stay (LOS) and provide outreach care over 24 months. Second, to demonstrate a cost saving and improved patient satisfaction.

\section{MAKING A CASE FOR CHANGE}

Preteam activity data for CYP with an ABI admitted for 7 days or more were collected and patient/family satisfaction feedback. We held stakeholder events including patient and families, therapy, managers (hospital and community), paediatric intensive care unit (PICU), neurosurgery, neurology and trauma colleagues. Issues identified were care far from home, infrequent therapy, no speech and language therapy (SLT) or psychology therapy or proactive discharge planning.

\section{IMPROVEMENTS}

We agreed a new pathway, funded by a pump priming initiative, appointed a dedicated team including physiotherapy, occupational therapy and SLT, neuropsychology with consultant leadership. All hospital teams were engaged. This specialist team provides early intensive rehabilitation, proactive parallel discharge planning (alongside acute care) through fortnightly multidisciplinary team meetings, communication with key child specific community colleagues (local authority, education and therapy) and postdischarge outreach home-based and outpatient care (figure 1). Over the reported cycles we made small changes, for example, e-referral, format of meetings (plan-do-study-act).

\section{OUTCOMES: CASE MIX}

Numbers, ages, gender and specialty case mix over 3 years' activity (table 1). Complexity of need as determined by 


\section{PRE TEAM}

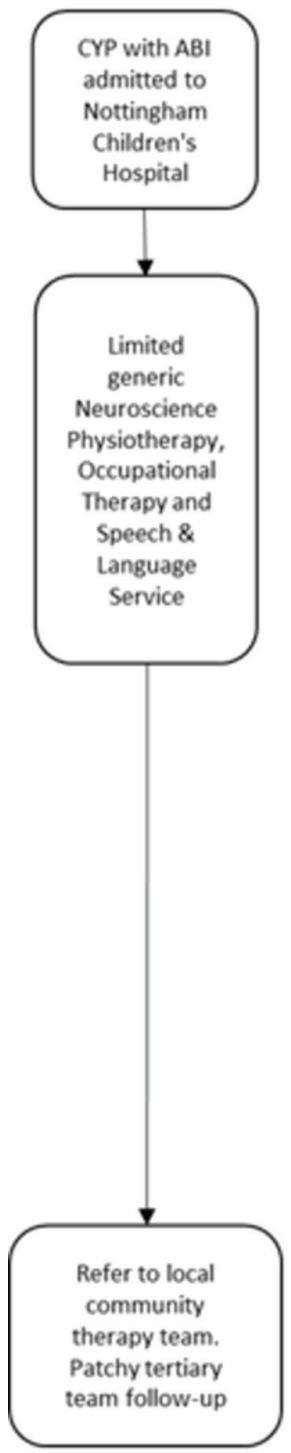

\section{PAEDIATRIC NEUROREHABILITATION SERVICE PATHWAY}

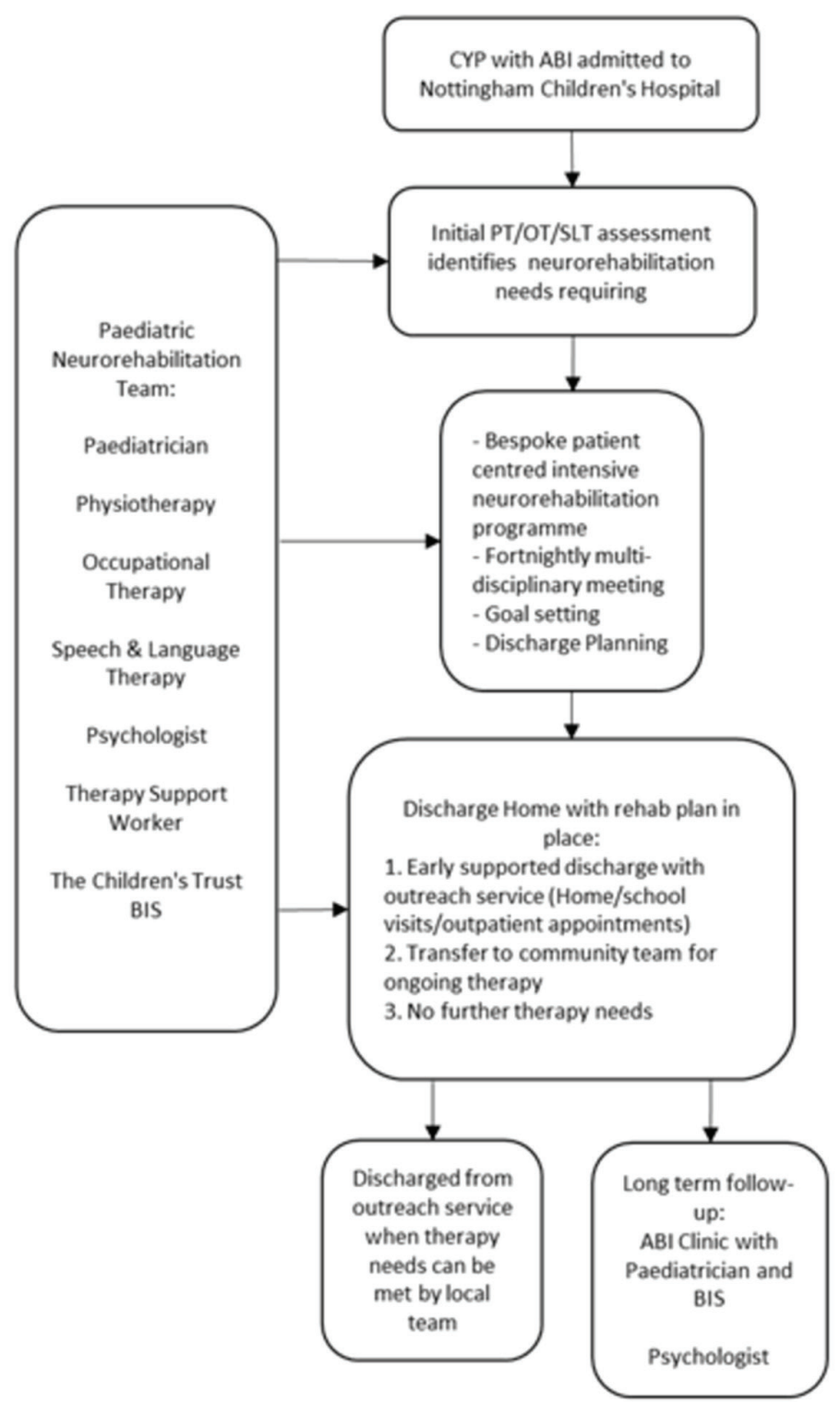

Figure 1 Neurorehabilitation pathway. ABI, acquired brain injury; BIS, brain injury specialist; CYP, children and young people; $\mathrm{OT}$, occupational therapy; PT, physiotherapy; SLT, speech and language therapy.

Table 1 Case mix, numbers of children and young people (CYP) and length of stay (days) by specialty

\begin{tabular}{|c|c|c|c|c|c|c|c|c|c|}
\hline \multirow[b]{2}{*}{ Year } & \multicolumn{3}{|l|}{$\operatorname{CYP}(n)$} & \multicolumn{3}{|l|}{ Total LOS } & \multicolumn{3}{|l|}{ Median LOS } \\
\hline & $2011 / 2012$ & $2014 / 2015$ & $2015 / 2016$ & $2011 / 2012$ & $2014 / 2015$ & $2015 / 2016$ & $2011 / 2012$ & $2014 / 2015$ & $2015 / 2016$ \\
\hline $\mathrm{n}=$ (male/female) & $43(22 / 21)$ & $49(35 / 14)$ & $50(33 / 17)$ & - & - & - & - & - & - \\
\hline Mean age (range) & $6.9(0-16)$ & $7.2(0-17)$ & $7.3(0-17)$ & - & - & - & - & - & - \\
\hline Days & - & - & - & 2642 & 2096 & 1303 & 31 & 19 & 17 \\
\hline Neuro -oncology & 17 & 12 & 10 & 1073 & 501 & 424 & 18 & 23.5 & 31 \\
\hline Neurosurgery & 8 & 12 & 15 & 279 & 384 & 227 & 21.5 & 13.5 & 11 \\
\hline Major trauma & 6 & 4 & 10 & 286 & 129 & 356 & 34 & 19.5 & 23 \\
\hline Neurology & 5 & 20 & 15 & 539 & 949 & 285 & 123 & 17.5 & 14 \\
\hline Other & 7 & 1 & 0 & 465 & 133 & 0 & 37 & 133 & 0 \\
\hline
\end{tabular}

LOS, length of stay. 


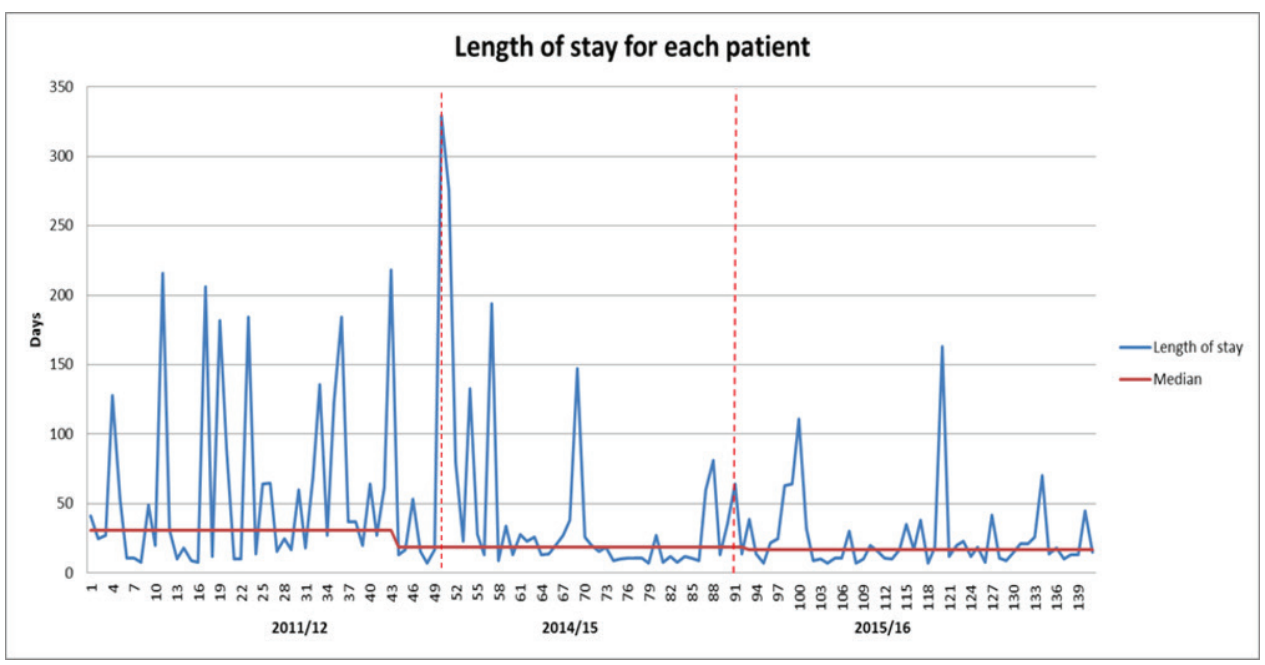

Figure 2 Run chart.

percentage referred from PICU/critical care unit being preteam 42\% (18/43), post-team year 2014/2015, 51\% (25/49), year 2015/2016, 40\% (20/50).

\section{Length of stay}

Our data collection shows that our intervention has led to a sustained reduction in LOS for our patient group. Preteam cumulative LOS 2642 days (median 31 days, IQR 16-69), post-team LOS for 2014/2015, 2096 days (median 19 days, IQR 13-34 days), LOS for 2015/2016, 1303 (median 17 days, IQR 11-29 days). The groups of similar size and demography were found to have a reduced LOS after introduction of team $(p=0.042014 / 2015, p=0.022015 / 2016)$. Some patients with complex needs stayed for more than 100 days. Controlling for age, gender, county of residence and specialty did not alter the cohort regression coefficient. These variables are not strong confounders. Twelve (27\%) CYP preteam vs 5 (10\%) CYP in 14/15, 7 (14\%) CYP in 2015/2016 were discharged back to their District general hospital (DGH) for ongoing medical management, for example, chemotherapy or safeguarding issues.

\section{Financial}

Assuming a bed-day equates to $£ 365$, the 546 days (2642-2096) saved 2014/2015 equivalent to $£ 199,290$ /year. For $2015 / 2016$ our analysis reflects $£ 488,735$ /yearversus team investment of $£ 179,174$. We have not included outpatient contact income in this cost benefit analysis.

\section{Family feedback}

Preteam response 12/43 (28\%) via a qualitative questionnaire included frustration with extended stays, lack of therapy, discharge planning and support. Postteam via Experience of Service Questionnaire (HI Commission for health improvement (CHI)) 35/99 (35\%) responded, including seven CYP (9-18 years), 97\% rating service at highest level as evidence of QI.

\section{DID OUR CHANGE CAUSE THIS EFFECT?}

We believe our changes caused the effect. Heightening hospital awareness and early referral was essential. There were no changes to our external partners; the cohorts themselves were similar. There is no evidence that reducing the LOS has reduced quality of care; no CYP needed readmission, there was no increase in DGH transfers. Benefits are ongoing (figure 2).

\section{LEARNING AND NEXT STEPS}

Involving key stakeholders, including users, in planning was crucial. Discharge from hospital still means rehabilitation continues through outpatient care. We regret not appointing initially a data and outcome analyst: we now consider this essential and are addressing this gap. Further studies comparing rehabilitation models of care in CYP with ABI are needed and have initiated a service evaluation study. It is critical that specialist units invest in therapy and psychology services to improve quality outcomes.

Acknowledgements We thank the families and young people for their feedback. The authors are grateful to Dr Andrea Venn, Honorable Associate Professor in Epidemiology and Medical Statistics, University of Nottingham, for statistical advice.

Collaborators Dr Andrea Venn, Honorable Associate Professor in Epidemiology and Medical Statistics, University of Nottingham.

Funding RK was awarded a CLHARC Silver Scholarship in 2018.

Competing interests None declared.

Patient consent Not required.

Provenance and peer review Not commissioned; externally peer reviewed.

Data sharing statement As a team we have no previous research published on this subject. We routinely collect data on our patients which are only available to clinicians in our organisation according to strict access guidelines.

Open access This is an open access article distributed in accordance with the Creative Commons Attribution Non Commercial (CC BY-NC 4.0) license, which permits others to distribute, remix, adapt, build upon this work noncommercially, and license their derivative works on different terms, provided the original work is properly cited, appropriate credit is given, any changes made indicated, and the use is non-commercial. See: http://creativecommons.org/ licenses/by-nc/4.0/.

ORCID ID 
Jane Williams http://orcid.org/0000-0001-6004-1523

\section{REFERENCES}

1 Hayes L, Shaw S, Pearce MS, et al. Requirements for and current provision of rehabilitation services for children after severe acquired brain injury in the UK: a population-based study. Arch Dis Child 2017;102:813-20.
2 NHS England National service specification paediatric neurorehabilitation Service specifications 2013; https:// www.england.nhs.uk/wp./06/e09-paedi-neurorehabilitation. pdf

3 Mayo NE, Wood-Dauphinee S, Côté R, et al. There's no place like home : an evaluation of early supported discharge for stroke. Stroke 2000;31:1016-23. 